\title{
Mental health epidemiology and services research. Contributions to US health care reform
}

\author{
DARREL A. REGIER
}

The United States recently engaged in a two year extensive review of health care policy with a view to reforming the health care delivery system. The availability of research data on total health care service use and costs under different financing and organizational arrangements helped support this review. Although research data were significant in the debate, the other important variables included political idealism or philosophy about the most appropriate role of government in health care; political pragmatism which required responses to constituency groups with a stake in the outcome; and the experience of constituents with government implementation of existing Medicaid and Medicare government health care programs (Regier, 1986). The contributions of both research and political variables to health care reform efforts will be reviewed briefly.

The starting gun for mental health care reform efforts sounded even before the Presidential election of 1992. Indicative of earlier interest was the fiscal year 1993 appropriations bill for NIMH, in which the Senate Committee on Appropriations requested a report on the cost of covering medical treatment for severe mental illness commensurate with other illnesses and an assessment of the efficacy of treatment of severe mental illness (Senate Report No. $102-397$, p. 96). This legislation included a definition of severe mental illness which included disorders with psychotic symptoms such as schizophrenia, schizoaffective disorder, manic depressive disorder, autism, as well as severe forms of other disorders such as major depression, panic disorder, and obsessive compulsive disorder. The NIMH aggregated several types of research information to address the

Indirizzo per la corrispondenza: Dr. D.A. Regier, Division of Epidemiology and Services Research, National Institute of Mental Health, 5600 Fishers Lane, 20857 Rockville MD (USA).

Fax $(+1) 301-4045$. request. The approach used included an assessment of research data on the prevalence of the defined severe mental disorders, the treated prevalence, the intensity of service utilization, the efficacy of treatment for these disorders, the current cost of care, and a projection of the cost of providing the same level of coverage for these disorders as is provided for physical disorders (National Advisory Mental Health Council, 1993). As this report was being completed in January 1993, President Clinton announced the formation of the President's Task Force on Health Care Reform in which a Mental Health Workgroup, under the leadership of Mrs. Tipper Gore, was an integral component.

With analyses from the Appropriations Committee report, the Mental Health Workgroup was well positioned to provide research based information on the scope of mental disorders in the population, service utilization patterns under different insurance plans, the aggregate cost of mental disorders, and the cost of specific benefit designs for acute care coverage. Examples of these data included the finding that $28 \%$ of the population could be identified as meeting DSM-III diagnostic criteria for a mental disorder in one year, about $11 \%$ received mental health services, $9 \%$ had some level of impairment, $2.8 \%$ had severe impairment, $1.7 \%$ had severe impairment and received mental health services, $0.9 \%$ had one or more in-patient admission, and $0.5 \%$ of the population received income support for disability associated with severe mental disorders (Regier et al., 1993; National Advisory Mental Health Council, 1993). Overall direct costs of mental health care were approximately 67 billion or $10 \%$ of total National health care expenditures an additional $2 \%$ of National health expenditures went for substance abuse services. Detailed clinical research reviews on the efficacy of treatments for severe mental disorders, provided as part of the Senate Report effort, 
showed that treatment response was in the same range as for physical disorders such as hypertension, diabetes, and coronary artery disease (National Institute of Mental Health, 1993). However, health insurance polices for medium and large private firms provided lower levels of reimbursement for mental disorders than physical disorders in $81 \%$ of plans for hospital care and $95 \%$ of plans for outpatient mental health care (Frank \& McGuire, 1994).

The major economic findings of the Senate Appropriations Committee Report were that it would be possible to increase the level of acute mental health services for the severely mentally ill to parity with physical illness for an additional annual cost of $\$ 6.5$ billion above the $\$ 20$ billion in 1990 expenditures for severe mental illness. Spread over the entire population, this would amount to less than $\$ 30$ per capita. However, such a change would still leave a substantial portion of chronic care (approximately $\$ 15$ billion including state Medicaid share) as the responsibility of State mental health authorities. Major differences in the level of State government spending on mental health are revealed by the low of $\$ 17$ per capita in Iowa to a high of $\$ 118$ per capita in New York, and a national median of $\$ 38$. Hence any national plan which would attempt to provide parity in chronic care services for mental illness in comparison with physical illness, would have to provide many of the same current services provided by State mental health authorities. Given the great diversity in funding and scope of such services in the different States, it was not politically feasible to develop a plan that would shift large sums of current State dollars to a uniform national plan. In the absence of a transfer of existing State funds, it would have been necessary for any National Health Insurance program to generate at least a comparable $\$ 15$ billion in new funds to assure the availability of the current level of chronic care for those with severe mental illness without even defining and addressing the issue of parity in chronic care for the mentally ill.

Although a great deal of attention was accorded to coverage of severe mental disorders, it was also necessary to focus on the cost of providing services for the full range of mental and addictive disorders. As a result of extensive actuarial experience in providing private insurance coverage for acute mental health treatment under various benefit package limits, it was possible to obtain consensus on the cost, for the currently insured, of a standard benefit package proposed as part of the President's Health
Security Act (HSA). However, obtaining reliable information for the cost of providing the same range of services for those currently uninsured proved far more difficult. In the absence of insurance information for these populations, it was necessary to rely on a recent NIMH supported epidemiological research study at the University of Michigan, (the National Co-morbidity Survey) and another NIMH National survey of mental hospital utilization. With these sources of data it was possible to narrow the estimate range for the uninsured and reduce the estimated cost of providing the HSA benefit to less than $10 \%$ of the total insurance premium cost a level considered acceptable by the Administration and the Congressional Committees which developed specific legislative proposals.

Despite the necessary contribution of epidemiologic and services research data to the health care reform debate, it was not sufficient to outweigh the political ideology, political pragmatism, and the impressions of Federal Government implementation expertise which the public had from previous experience with Medicare and Medicaid. Ideological political concerns were focused on government mandates that employers would have to provide insurance to all employees, and that large health insurance purchasing cooperatives would oversee newly organized accountable health plans in order to increase competition and efficiency. Although most large to mid-sized companies already provide insurance to their employees and large group practices have achieved considerable public acceptance, the proposed increase in government monitoring and control of the health system precipitated a major ideological debate that was independent of any research findings. Another ideological issue included the conviction of some State Mental Health Commissioners that the coordination of the multiple treatment, vocational rehabilitation, and assisted housing, that are a part of chronic care for the severe mentally ill, should more appropriately be coordinated as a State or local government function. Since some States were actively experimenting with contracting out such functions to private group practice or managed care companies, the lack of consensus on this ideological issue proved to be a detriment for achieving political action.

Pragmatic political considerations included the potential cost to small businesses of insuring their employees, and the potential loss of business for the health insurance industry. These two groups mounted historic political campaigns which were consider- 
ed to be remarkably effective in reversing the momentum toward health care reform. The health insurance industry television adds of Harry and Louise decrying the incursion of government into health care have now become part of American folklore.

A final variable in the health care reform debate was the experience of the public and their elected representatives with the current Federal government health insurance programs of Medicare and Medicaid. Although both of these programs have a great deal of popular political support, they have both been marked by major increases in cost over the past few years. In order to control these costs, they have imposed reimbursement rate limitations which have tended to shift costs to the private sector. Because of lower reimbursement rates, many physicians refuse to accept patients under Medicare and Medicaid which significantly reduces the range of providers available to individuals insured under these plans. Although a truly comprehensive national health plan, which combined public and private components of the health care, would eliminate cost shifting and allow greater controls for cost increases, no consensus emerged for a single-payer national health insurance plan. As a result of these concerns, there was no support for a major expansion of Medicare and Medicaid programs in the absence of a comprehensive reform.

In summary, research information, political ideology, political pragmatism, and implementation expertise may be seen as the independent variables contributing to the dependent variable of health care reform. In the recent US experience, it was encouraging that the availability of an extensive array of epidemiologic, services research, and actuarial data kept mental health services as a viable compo- nent of virtually all administration and congressional proposals. Gaps in the data which were exposed in this intense process are currently being addressed in new research efforts particularly in the areas of improving our knowledge of child and adolescent mental and addictive treatments, and in the area of risk adjustment to predict resource needs of severely ill members of the population. Hence, when the other variables are once again aligned to address significant reforms in the US health care system, we hope to be able to improve the level of contribution which will be forthcoming from the research community.

\section{REFERENCES}

Frank R.G. \& McGuire T.G. (1994). Health care reform and financing of mental health services: distributional cnsequences. In Mental Health, United States, 1994 (ed. R.W. Manderscheid and M.A. Sonnenschein). Department of Health and Human Services Publication No. (SMA) 94-3000. US Government Printing Office: Washington, DC.

,National Advisory Mental Health Council (1993). Health care reform for Americans with severe mental illnesses: report of the National Advisory Mental Health Council. American Journal of Psychiatry 150, 1447-1465.

National Institute of Mental Health (1993). The Value of Psychiatric Treatments: Its Efficacy in Severe Mental Disorders. Special issue in Psychopharmacology Bulletin 29, No. 4.

Regier D.A. (1986). Mental health service policy implications of epidemiologic data. In Mental Disorders in the Community (ed. J. Barrett and R.M. Rose). Guilford: New York.

Regier D.A., Narrow W.E., Rae D.S., Manderscheid R.W., Locke B.Z. \& Goodwin F.K. (1993). The de facto mental and addictive disorders service system. Archives of General Psychiatry 50, 85-94. 